\title{
Difference in CXCR4 expression between sporadic and VHL-related hemangioblastoma
}

\author{
Roeliene C. Kruizinga ${ }^{1,2}$ - Denise M. S. van Marion ${ }^{1}$ - Wilfred F. A. den Dunnen ${ }^{3}$. \\ Jan C. de Groot ${ }^{4}$ Eelco W. Hoving ${ }^{5}$ Sjoukje F. Oosting ${ }^{1} \cdot$ Hetty Timmer-Bosscha $^{1}$. \\ Rosalie P. H. Derks ${ }^{4}$. Chantal Cornelissen ${ }^{6} \cdot$ Rob B. van der Luijt ${ }^{6}$. \\ Thera P. Links ${ }^{2}$ Elisabeth G. E. de Vries ${ }^{1}$ - Annemiek M. E. Walenkamp ${ }^{1}$
}

Published online: 26 February 2016

(c) The Author(s) 2016. This article is published with open access at Springerlink.com

\begin{abstract}
Central nervous system hemangioblastomas occur sporadically and in patients with von Hippel-Lindau (VHL) disease due to a $V H L$ germline mutation. This mutation leads to enhanced transcription of chemokine receptor 4 (CXCR4), its ligand (CXCL12) and vascular endothelial growth factor A (VEGFA). We aimed to determine in VHL-related and sporadic hemangioblastomas CXCR4, CXCL12, and VEGFA protein expression and to correlate this to hemangioblastoma size and expression in normal surrounding tissue. 27 patients with a hemangioblastoma were included for analysis of immunohistochemistry of tissue, MRI and DNA. Hemangioblastomas overexpress CXCR4, CXCL12, and VEGFA compared to normal surrounding tissue. In sporadic hemangioblastomas the mean percentage of CXCR4
\end{abstract}

Portions of this work were presented in poster form at the AACR conference, Washington, USA, April 2013.

Roeliene C. Kruizinga and Denise M. S. van Marion have contributed equally to this work.

Electronic supplementary material The online version of this article (doi:10.1007/s10689-016-9879-3) contains supplementary material, which is available to authorized users.

Annemiek M. E. Walenkamp

a.walenkamp@umcg.nl

1 Department of Medical Oncology, University Medical Center Groningen, University of Groningen, P.O. Box 30.001, 9700 RB Groningen, The Netherlands

2 Department of Endocrinology, University Medical Center Groningen, University of Groningen, P.O. Box 30.001, 9700 RB Groningen, The Netherlands

3 Department of Pathology, University Medical Center Groningen, University of Groningen, P.O. Box 30.001, 9700 RB Groningen, The Netherlands positive hemangioblastoma cells was $16 \%, \mathrm{SD} 8.4$, in VHL-related hemangioblastomas $8 \%, \quad$ SD 4.4 $(P=0.002)$. There was no relation between preoperative tumor size and CXCR4 or CXCL12 expression. Compared to normal surrounding tissue CXCR4, CXCL12, and VEGFA were overexpressed in hemangioblastomas. Most interestingly, sporadic hemangioblastomas overexpress CXCR4 compared to VHL-related hemangioblastoma.

Keywords CXCR4 - CXCL12 - Hemangioblastomas · VEGF · VHL

\section{Introduction}

von Hippel-Lindau (VHL) disease is an autosomal dominant syndrome leading to the onset of multi-organ benign and malignant neoplasms including hemangioblastomas. Hemangioblastomas are highly vascularized lesions comprising 1.1-2.4\% of central nervous system (CNS) neoplasms. Their principal components are hemangioblastoma stromal cells with a low mitotic index and capillaries

4 Department of Radiology, University Medical Center Groningen, University of Groningen, P.O. Box 30.001, 9700 RB Groningen, The Netherlands

5 Department of Neurosurgery, University Medical Center Groningen, University of Groningen, P.O. Box 30.001, 9700 RB Groningen, The Netherlands

6 Department of Medical Genetics, University Medical Center Utrecht, P.O. Box 85.500, 3508 GA Utrecht, The Netherlands 
formed by normal endothelial cells with activated pericyte coverage. Approximately a third of hemangioblastomas is related to VHL-disease [1]. However, this might be an underestimation as not all cases are screened for germ-line VHL-mutations.

The characteristic vascularized appearance of hemangioblastomas in VHL-disease patients is thought to be caused by the VHL-mutation leading to defective or absent VHL protein (pVHL). Improper functioning $\mathrm{pVHL}$ fails to degrade hypoxia inducible factor 1A (HIF1A) thereby resulting in increased transcription of proteins such as platelet-derived growth factor, transforming growth factor A and vascular endothelial growth factor (VEGFA) [2-4]. Upon expression VEGFA is released into the environment by the tumor cells and binds to its corresponding receptors mainly on endothelial cells. In this way VEGFA primarily induces endothelial cell proliferation and migration, promoting the aberrant angiogenesis that supports tumor growth and tumor metastasis [5].

Several in vitro and in vivo models have revealed a key role of chemokine receptor 4 (CXCR4) and its ligand CXCL12 in the crosstalking between cancer cells and their microenvironment $[6,7]$. CXCR4 is downregulated by the VHL protein and upregulated by HIF1A. CXCR4 and CXCL12 are co-expressed in CNS hemangioblastoma and in renal clear cell carcinoma [8]. Large tumors have more risk on hypoxic conditions. Increased hypoxia leads to higher CXCR4 expression via HIF1 $\alpha$. Loss-of-function of the $V H L$ gene is responsible for the upregulation of the expression of CXCR4, its ligand CXLC12, and VEGFA. This is particularly interesting as these micro-environmental factors are increasingly recognized and established as novel drug targets [9].

Therefore, the aim of this study was to investigate CXCR4, CXCL12, and VEGFA protein expression in VHL-related and sporadic hemangioblastomas and to correlate this to size as measured by MRI before surgery to investigate possible differences between VHL-related and sporadic hemangioblastoma. In order to verify the contribution of somatic $V H L$ mutations and hypermethylation of hemangioblastomas we analyzed $V H L$ mutations and promoter methylation in the tumor tissue.

\section{Materials and methods}

\section{Patients}

All patients that were operated between 1995 and 2010 in the University Medical Center Groningen from who frozen hemangioblastoma tissue was available in the tissue bank of the Department of Pathology were eligible. Patients without a known germline mutation were classified as having sporadic hemangioblastoma and patient with a known germline mutation were as having VHL-related hemangioblastoma. All patients apart from one, who refused screening for germline $V H L$-mutation, were routinely tested for mutations.

Hemangioblastoma tissues were numerically tagged according to a national coding system. Clinical data obtained from VHL surveillance were used to retrieve data on gender and age. Lesion size of both solid nodule and associated cyst size were based on pre-operative MRI scan and on written surgery reports. According to the VHL guidelines, MRI scans from the cerebellum and myelum were performed biennially [10-13], annually when a lesion was present, and every 6 months when a lesion was found to have increased in size until stable disease was ascertained (www.stoet.nl, VHL working group). The largest diameter in $\mathrm{mm}$ was used and surface area in $\mathrm{mm}^{2}$ was then calculated. Solid tumor size was defined by the diameter of only the solid nodule and cyst size by only the cystic part. Total size was defined by largest diameter of both solid and cystic part together. All data was stored in a computerized anonymous database. Patient identity was protected by unique codes. The Medical Ethical Review Board declared that based on Dutch law no further approval for use of residual tissue for analysis, including DNA analysis, was needed.

\section{Immunohistochemistry}

Cryosections $(4 \mu \mathrm{m})$ were morphologically defined as hemangioblastoma by hematoxylin and eosin (H\&E) staining. For CXCR4, CXCL12, and VEGFA staining, the fixation procedure was followed by endogenous peroxidase blockage by $1 \%(\mathrm{w} / \mathrm{v})$ hydrogen peroxidase. CXCR 4 was stained in dilution 1:500 (polyclonal rabbit \#ab2074, Abcam, Cambridge, UK) and CXCL12 in dilution 1:60 (monoclonal mouse \#MAB350, R\&D Systems, Abingdon, UK). VEGFA staining was performed using the avidinbiotin complex method (avidin-biotin blocking kit, Vector Laboratories, Peterborough, UK) with anti-VEGFA as primary antibody in dilution 1:50 (polyclonal rabbit \#sc152, Santa Cruz, Heidelberg, Germany). All secondary and tertiary goat anti rabbit horse radish peroxidase (HRP), rabbit anti goat HRP and rabbit anti mouse HRP, secondary swine anti rabbit biotinylated antibodies and streptavidinHRP were obtained from Dako (Glostrup, Denmark). Frozen sections of glioblastoma (WHO grade 4) served as positive controls for CXCR4 and VEGFA. Cytospins of renal cell carcinoma cells (RCC786, authenticated by STR analysis) served as the positive controls for CXCL12. For negative controls, the primary antibodies were omitted. 
Normal surrounding brain tissue, small fragments of preexistent normal brain parenchyma excised during debulking surgery, was verified by morphology on H\&E staining. CXCR4 quantitative evaluation was performed by counting the percentage of positive cells (of total cells) in 5 random, but qualitatively good, high power fields $(400 \times$ magnification) per hemangioblastoma slide. CXCL12 semi quantitative evaluation was performed in 5 high power fields $(400 \times$ magnification) per slide and defined as negative, positive ( $>1 \%$ positive cells) or strongly positive ( $>50 \%$ positive cells or high intensity). VEGFA was evaluated by describing morphology of tissue (normal brain tissue, vascular endothelium and stromal hemangioblastoma cells) in relation to positive cells. Evaluation and quantification was performed by two independent observers (RCK and NK) blinded to the diagnosis, using NDP software (Hamamatsu, Almere, the Netherlands) after scanning slides with a Hamamatsu scanner (Hamamatsu).

\section{DNA isolation}

For DNA isolation frozen hemangioblastoma scrapings (10 times $10 \mu \mathrm{m}$ ) were collected from all 33 hemangioblastomas. Also 2 male and 2 female samples of normal tissue were collected. DNA was extracted using dissolving buffer [ $4 \mathrm{~mol} / \mathrm{l}$ guanidine thiocyanate-buffer, DNase free water, $96 \%$ ethanol and further digested in Tris EDTA (TE)buffer $(10 \mathrm{mmol} / 1 \mathrm{Tris} / \mathrm{HCl}, \mathrm{pH}=7.5,1 \mathrm{mmol} / \mathrm{l}$ EDTA with proteinase $\mathrm{K}$ and sodium dodecyl sulfate $10 \%$ (w/ v))]. Standard salt extraction and isopropanol precipitation was used for high molecular DNA and dissolved in $150 \mu \mathrm{l}$ TE-buffer. For quality control, genomic DNA was amplified in a multiplex PCR according to the BIOMED-2 protocol [14].

\section{Sequencing and multiplex ligation-dependent probe amplification (MLPA)}

Germline mutations were defined by inherited mutations in $V H L$ or inherited loss of the whole gene as found in loss of heterozygosity (LOH) analysis. Exons 1, 2 and 3 of $V H L$ and their flanking sequences were amplified by PCR. PCR products were purified and subjected to sequence analysis using an ABI 3730 automated DNA sequencer (Applied Biosystems, Life Technologies Corporation, CA, USA). To detect genomic deletions involving single or multiple exons of $V H L$, an MLPA-assay (MRC-Holland SALSA MLPA P016 VHL probe mix, Amsterdam, the Netherlands) was performed according to the manufacturer's instructions. For the interpretation of sequence alterations, the Alamut (Interactive Biosoftware, Rouen, France) decision-support software package was used.

\section{Methylation specific PCR (MSP)}

MSP was performed after bisulphite treatment on denatured genomic DNA. Bisulphite treatment was performed with the EZ DNA methylation kit according the manufacturer's protocol (Zymogen, BaseClear, Leiden, the Netherlands). For PCR $15 \mathrm{ng}$ of bisulphite treated DNA was used. The $\beta$-actin gene served as an internal reference. Primer pair sequences are listed in Supplementary Table 2 (designed with Methyl Primer Express v1.0, Invitrogen). PCR products were visualized on a $2.5 \%(\mathrm{w} / \mathrm{v})$ agarose gel. A sample was considered positive (methylated or hypermethylated) when a PCR product of the right size was visible after 40 cycles of PCR. Leukocyte DNA collected from anonymous healthy volunteers and in vitro $\mathrm{CpG}$ methylated DNA with SssI (CpG) methyltransferase (New England Biolabs Inc., Beverly, MA, USA) were used as negative and positive control, respectively.

\section{Statistical analysis}

Statistical analysis was done using Kruskal-Wallis test, linear regression and Spearman rank correlation. $P$ values of $<0.05$ were considered significant.

\section{Results}

Thirty-three specimens of 27 patients operated between 1995 and 2010 for central nervous system hemangioblastoma were analyzed. Sixteen specimens were from 11 VHL-disease patients (seven with 1, three with 2 and one patient with 3 specimens) and 17 specimens from 16 sporadic cases (15 with 1 and one with 2 specimens) (Table 1).

In 27 specimens sufficient DNA was available to perform mutation analysis (Table 2, Supplementary Table 1). In $76.9 \%$ of cases (10 out of 13) of VHL-related hemangioblastomas only the germline mutation was found, in $15.4 \%$ ( 2 out of 13) two mutations were present (second hit) and in one case 3 mutations were found. In the sporadic hemangioblastomas, $57 \%$ (8 out of 14) were mutated. In two out of 27 hemangioblastomas specimens the VHL promoter was hypermethylated, both were sporadic hemangioblastoma cases (Fig. 1).

\section{CXCR4, CXCL12 and VEGFA expression}

All hemangioblastoma cells, excluding endothelial cells, showed CXCR4 expression $(n=29$, as 4 slides were not evaluable; Fig. 2A). In the 16 sporadic hemangioblastomas the mean percentage of CXCR4 positive cells per specimen (16\%, range 1-38\%) was higher as compared to the 13 VHL-related hemangioblastomas (8\%, range 3-19\%, 
Table 1 Characteristics of hemangioblastoma patients and their tissues

\begin{tabular}{|c|c|c|c|}
\hline Characteristic & $\begin{array}{l}\text { No of } \\
\text { tissues }(\%)\end{array}$ & $\begin{array}{l}\text { No of } \\
\text { patients }(\%)\end{array}$ & $\begin{array}{l}\text { Age at time of surgery } \\
\text { in years (range) }\end{array}$ \\
\hline \multicolumn{4}{|l|}{ Sex } \\
\hline Male & $21(64 \%)$ & 17 & $47(13-62)$ \\
\hline Female & $12(36 \%)$ & 10 & $41(14-65)$ \\
\hline$V H L$-mutation carriers & $16(48 \%)$ & $11(41 \%)$ & $46(26-65)$ \\
\hline c.259_260-insA p.Val87Aspfs*45 & $1(6 \%)$ & & \\
\hline c.-89-?_c297+?del. p(?) & $7(44 \%)$ & & \\
\hline c.341-59_341-14del p.? & $1(6 \%)$ & & \\
\hline c. $462 \mathrm{~A}>$ C p.Pro154Pro & $1(6 \%)$ & & \\
\hline c.500G $>$ A p.Arg167Gln & $3(19 \%)$ & & \\
\hline c. $463+2 \mathrm{~T}>\mathrm{C}$ p.(?) & $1(6 \%)$ & & \\
\hline c. $490 \mathrm{C}>\mathrm{T}$ p.Gln164* & $2(13 \%)$ & & \\
\hline Sporadic & $17(52 \%)$ & $16(59 \%)$ & $44(13-62)$ \\
\hline
\end{tabular}

Table 2 Occurrence of $V H L$-mutations and CXCR4 expression in the hemangioblastoma (HB) specimens

\begin{tabular}{|c|c|c|c|c|}
\hline & \multicolumn{2}{|c|}{ VHL-related HB } & \multicolumn{2}{|l|}{ Sporadic HB } \\
\hline & $\begin{array}{l}\text { Percentage } \\
\text { (number) }\end{array}$ & $\begin{array}{l}\text { CXCR4 expression } \\
\text { (\% post. cells) }\end{array}$ & $\begin{array}{l}\text { Percentage } \\
\text { (number) }\end{array}$ & $\begin{array}{l}\text { CXCR } 4 \text { expression } \\
\text { (\% post. cells) }\end{array}$ \\
\hline Two normal alleles & - & - & $43(6 / 14)$ & 17.0 \\
\hline One mutation & $76.9(10 / 13)$ & 8.2 & $14.3(2 / 14)$ & 16.5 \\
\hline Two mutations & $15.4(2 / 13)$ & 10.2 & $7.1(1 / 14)$ & 16.1 \\
\hline $\mathrm{LOH}$ & 0 & - & $21.4(3 / 14)$ & 24.5 \\
\hline One mutation and $\mathrm{LOH}$ & 0 & - & $14.3(2 / 14)$ & 12.1 \\
\hline Three mutations & $7.7(1 / 13)$ & 7.3 & 0 & - \\
\hline
\end{tabular}
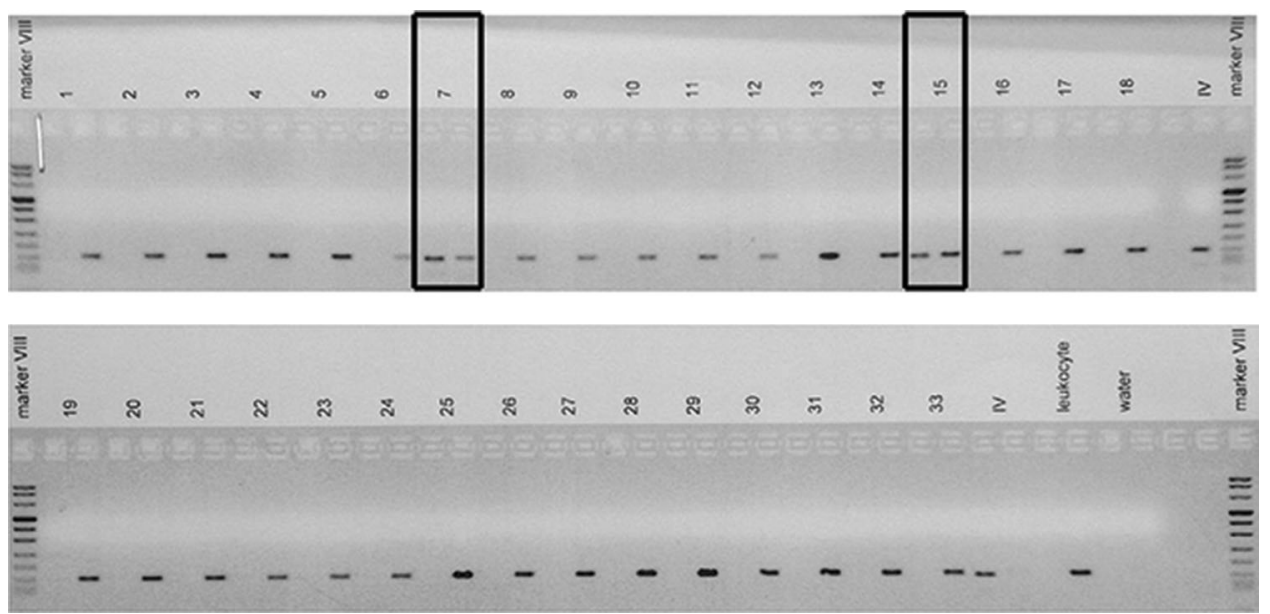

Fig. 1 All VHL methylation specific PCR (MSP) products, 33 hemangioblastoma tissues (numbered 1-17 sporadic cases, 18-33 VHL related cases) and controls (in vitro $\mathrm{CpG}$ methylated DNA with Sssl CpG methyltransferase (IV), leukocyte and water), on agarose gel. From each sample the first lane is the methylated DNA and the second lane the unmethylated DNA. Hemangioblastoma derived DNA sample 7 and 15 (boxes) show methylation of the $V H L$ promoter, both these samples were derived from sporadic hemangioblastoma patients. Experiments were performed in triplicate 
$P=0.002$; Fig. $2 b$; Table 2). In the 15 available normal surrounding brain tissue samples no CXCR4 expression was observed.

Thirty two samples were evaluable for CXCL12 expression. Sporadic and VHL-related hemangioblastomas had the same level of CXCL12 expression (Fig. 2c), with strong expression in $75 \%$ (12 out of 16) of sporadic hemangioblastomas and in $81 \%$ (13 out of 16) of VHLrelated hemangioblastoma cells. The normal tissue showed no $(\mathrm{n}=12)$ or in a few cases $(\mathrm{n}=3)$ some expression of CXCL12 (Fig. 3). VEGFA was expressed higher than normal in sporadic and VHL-related hemangioblastomas, and present in stromal hemangioblastoma cells and vascular endothelial cells (Fig. 4).

\section{Correlation between CXCR4 expression and clinical variables}

Sporadic hemangioblastomas and associated cyst size did not differ from VHL-related hemangioblastomas (sporadic: median solid tumor size $547.5 \mathrm{~mm}^{2}$, median total size

A

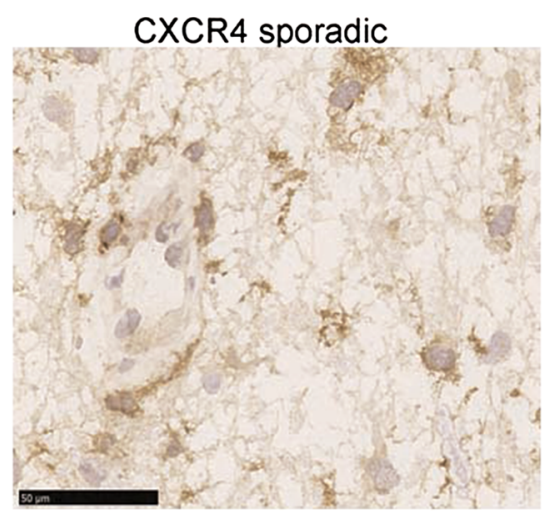

B

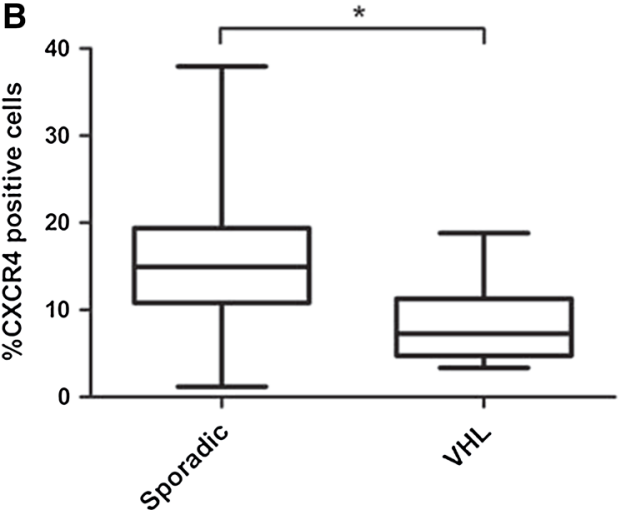

Fig. 2 a Representative pictures CXCR4 immunohistochemistry ( $\times 40$ magnification) on sporadic (left) and VHL-disease related (right) hemangioblastoma specimens. CXCR4 expression is present in all hemangioblastoma cells, excluding endothelial cells [vessels are depicted by an asterisk (*)]. b, c Box plots of percentage of CXCR4 positive cells (b) and CXCL12 staining intensity (c) per field of view
$1316.3 \mathrm{~mm}^{2}$ and VHL-related: median solid tumor size $235.75 \mathrm{~mm}^{2}$, and median total size $545.88 \mathrm{~mm}^{2}, P=0.09$ for both; Fig. 5).

The tumor and associated cyst size was not correlated to the CXCR4 expression level $(95 \%$ confidence interval $298.8 ; 700.1 \mathrm{~mm}^{2}$ rho $=0.39, P=0.069$ for tumor nodule and $95 \%$ confidence interval $763.7 ; 1295.5 \mathrm{~mm}^{2}$ rho $=0.095, P=0.644$ for total size; Fig. 5).

\section{Discussion}

This study shows that CXCR4, CXCL12, and VEGFA are all overexpressed in stromal hemangioblastoma cells compared to normal surrounding brain tissue. This is the first study in which expression of CXCR4, CXCL12, and VEGFA is compared in both sporadic and VHL associated hemangioblastoma patients. Earlier studies in VHL related hemangioblastoma found upregulated CXCR4, CXCL12, and VEGFA. In contrast, studies in VHL-related renal cell carcinoma and retinal hemangioblastoma high levels of
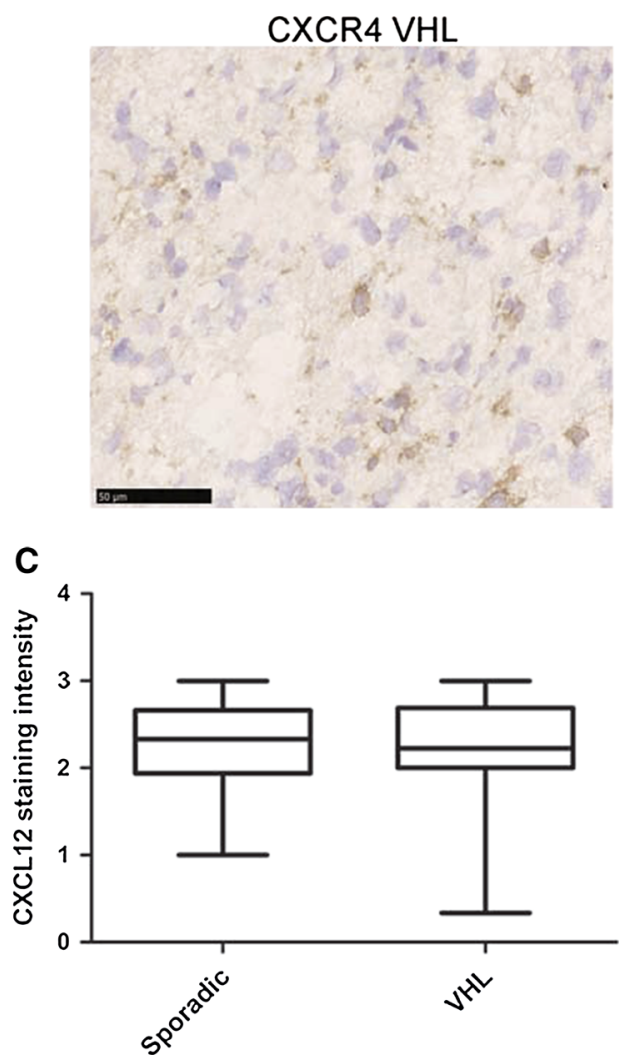

in sporadic and VHL-disease related hemangioblastoma specimens showing a higher mean percentage of CXCR4 positive cells but similar CXCL12 expression in sporadic hemangioblastoma compared to VHL-related hemangioblastoma. Linear regression, $* P<0.05$. The bars represent the range 

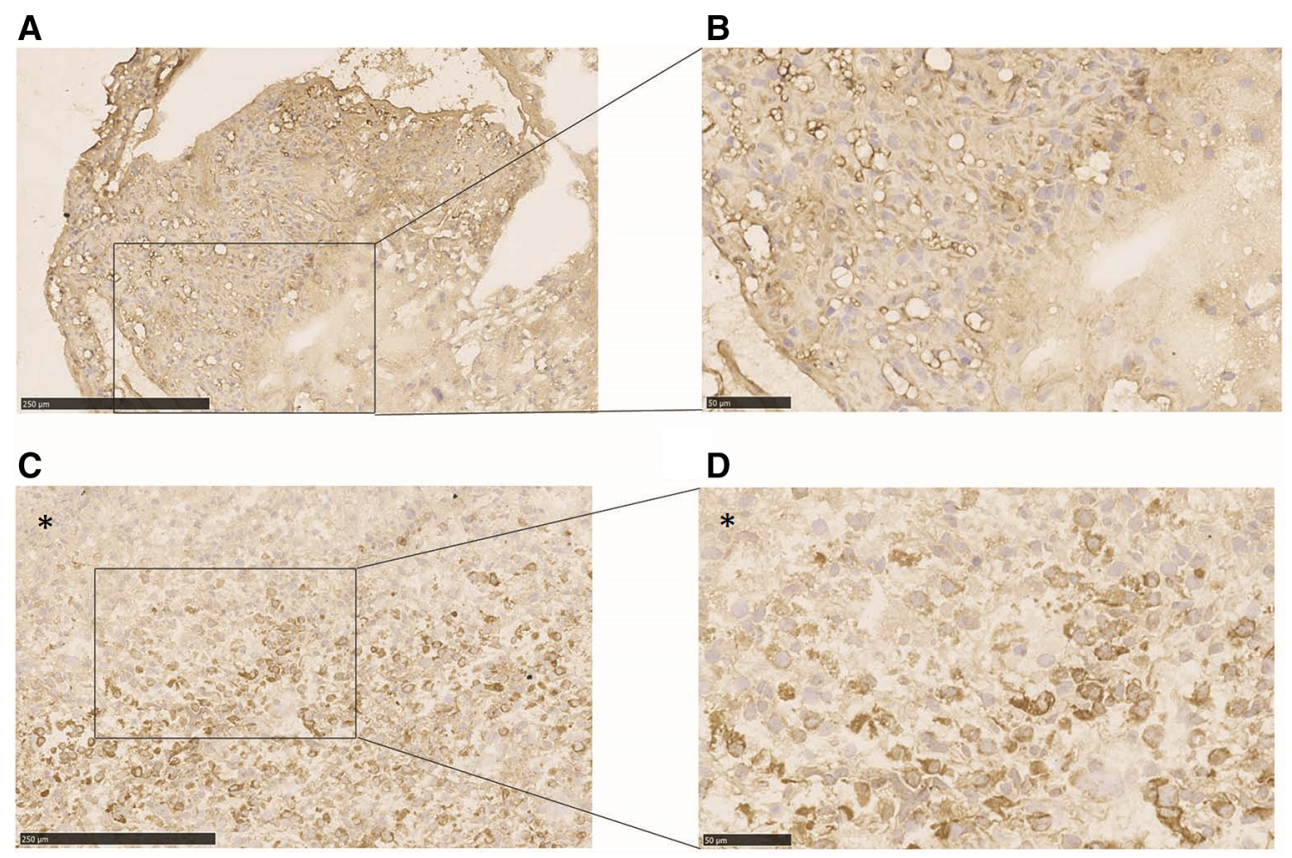

Fig. 3 Hemangioblastoma tissue overexpresses CXCL12 compared to normal tissue as depicted in the representative pictures of CXCL12 immunohistochemistry on VHL-disease $(\mathbf{a} \times 40$ magnification and b computer magnification) and hemangioblastoma $(\mathbf{c} \times 40$ magnification and $\mathbf{d}$ computer magnification) specimens [normal tissue within hemangioblastoma specimen depicted by an asterisk (*)]
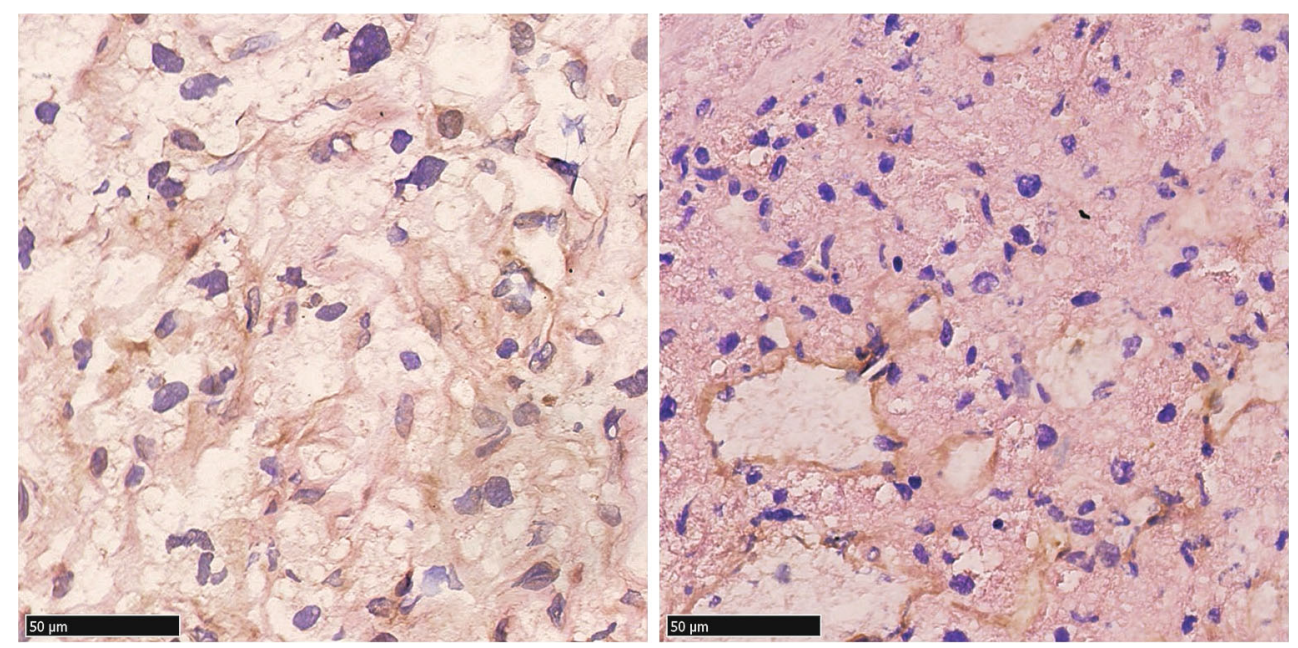

Fig. 4 Stromal hemangioblastoma cells and vascular endothelial cells show higher immunohistochemical ( $\times 40$ magnification) VEGFA expression in sporadic (left) and VHL-related (right) than normal tissue in hemangioblastoma specimens

CXCR4 and VEGF, and not CXCL12, were found [15-17]. In the current study CXCL12 and VEGFA expression was similar in sporadic and VHL-related cases.

The finding that CXCR4 expression was higher in sporadic hemangioblastomas is striking as in VHL-disease a germline mutation in $V H L$ leads to a defect VHL protein which results in enhanced transcription of CXCR4, its ligand CXCL12 as well as VEGFA [8]. To analyze the possible reason for the observed difference we determined the genetic background of hemangioblastomas of both
VHL-related and sporadic cases. The onset of lesion formation in VHL-disease occurs when the inherited germline mutation is accompanied by a second hit, e.g. a mutation in the normal allele. Previous studies reported inactivation of both alleles of VHL in 62 of VHL-disease related hemangioblastoma [20]. For VHL-related renal cell carcinoma this percentage is even higher, $86.6 \%$ [21]. In sporadic hemangioblastomas $V H L$ is inactivated as well. Others reported that in 20-50 \% of cases one allele was inactivated and in $0-13 \%$ both $V H L$ alleles [20, 22-27]. Our 

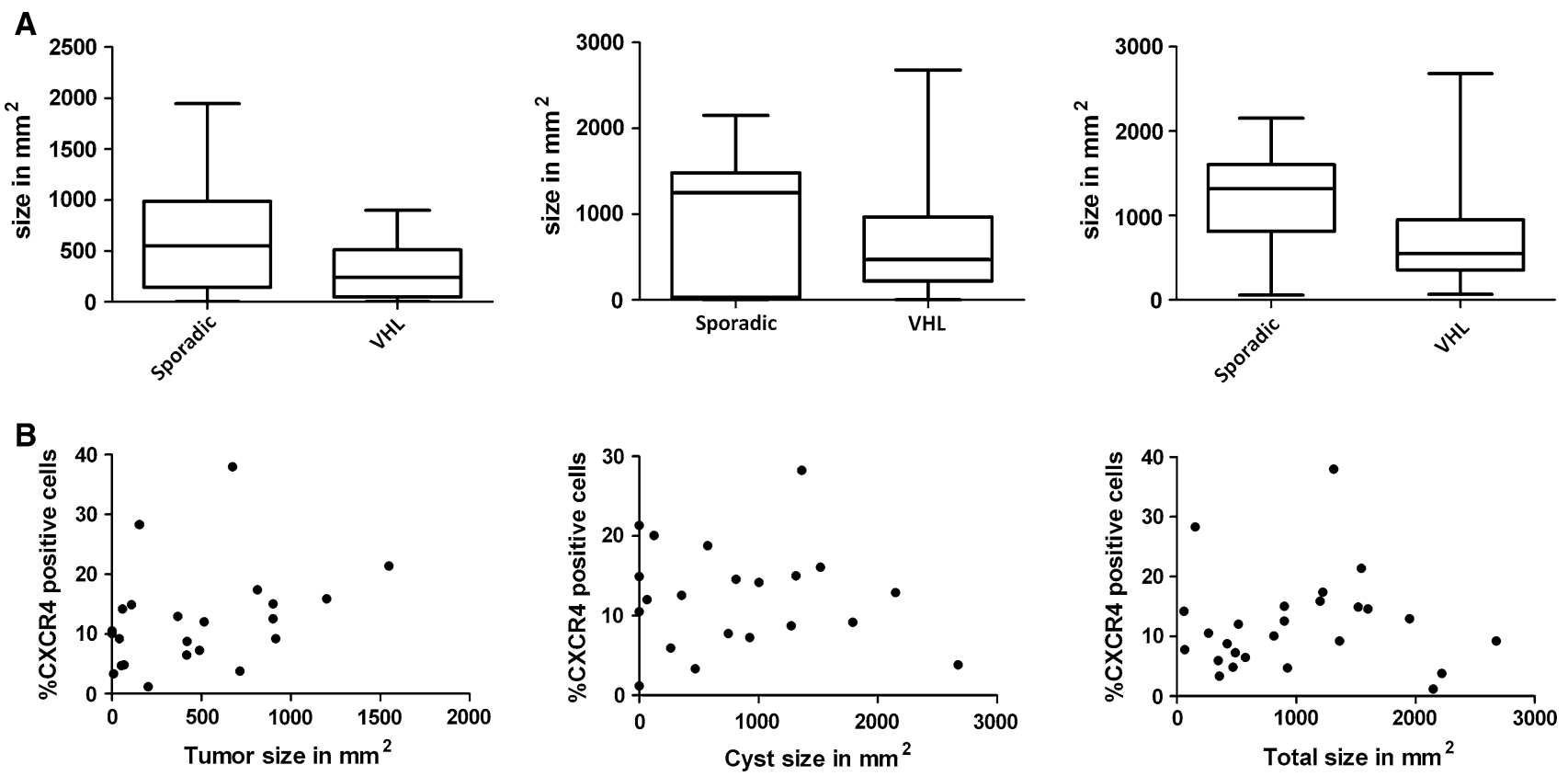

Fig. 5 a Boxplots of size in $\mathrm{mm}^{2}$ of solid tumor (left), cyst (middle) and largest total diameter (right) of the sporadic and VHL-disease related hemangioblastoma specimens, measured on pre-operative MRI images (bars represent the range). Hemangioblastomas and associated cyst size was similar for sporadic and VHL-related hemangioblastoma specimens. b Solid tumor (left), cyst (middle) and total (right) hemangioblastoma size in $\mathrm{mm}^{2}$ and the percentage of CXCR4 positive cells per field of view measured by CXCR4 immunohistochemistry were not correlated data show that in all VHL-related and in the majority of sporadic hemangioblastomas a mutation, LOH or hypermethylation of the $V H L$ was present. In addition no difference in CXCR4 expression between patients with and without a $V H L$-mutation was found and thus could not explain the observed difference in CXCR4 expression in VHL and sporadic hemangioblastomas.

Next we hypothesized that the size of hemangioblastomas at the time of surgery might explain the observed difference in CXCR4 expression and analyzed MRIs for hemangioblastoma size. Bulky tumors develop more hypoxia then smaller ones. Therefore, bulky tumors, with more hypoxia, are hypothesized to express higher levels of CXCR4, as hypoxia and CXCR4 upregulation are correlated [15]. Hypoxia has been found to be inversely correlated to tumor size in murine models $[18,19]$. Although VHL patients are screened by biennial MRI [10-13] we did not find a significant difference in preoperative size of VHL-related and sporadic hemangioblastomas and associated cysts.

We also determined the genetic background of hemangioblastomas of both VHL-related and sporadic cases. The onset of lesion formation in VHL-disease occurs when the inherited germline mutation is accompanied by a second hit, e.g. a mutation in the normal allele. Previous studies reported inactivation of both alleles of VHL in 62 of VHL- disease related hemangioblastoma [20]. For VHL-related renal cell carcinoma this percentage is even higher, $86.6 \%$ [21]. In sporadic hemangioblastomas $V H L$ is inactivated as well. Others reported that in 20-50 \% of cases one allele was inactivated and in 0-13\% both $V H L$ alleles [20, 22-27]. Our data show that in all VHL-related and in the majority of sporadic hemangioblastomas a mutation, $\mathrm{LOH}$ or hypermethylation of the $V H L$ was present. In addition no difference in CXCR4 expression between patients with and without a VHLmutation was found and thus could not explain the observed difference in CXCR4 expression in VHL and sporadic hemangioblastomas.

We and others found CXCR4 overexpressed in hemangioblastoma cells compared to normal surrounding brain tissue [8]. The difference in CXCR4 expression between these two cell types might be caused by their difference in origin, the hemangioblastoma cell is a mesoderm-derived, embryologically arrested hemangioblast [22]. As the CXCR4 expression is limited to hemangioblastoma tissue, this potentially creates opportunities for treatment with drugs specifically targeting CXCR4 expressing cells. Since CXCR4 expression is involved in primary tumor growth [28], tumor invasiveness [29], metastasis [29], angiogenesis [30] and vasculogenesis [31], this subpopulation of CXCR4 overexpressing cells can be targeted by CXCR4 inhibitors. The tumor growth-stimulating role of CXCR4 
was confirmed by showing that CXCR4 antagonists inhibit tumor growth in multiple experimental orthotopic, subcutaneous human xenograft, and transgenic mouse models [32]. In a transgenic breast cancer mouse model, treatment with the CXCR4 inhibition CTCE-9908 resulted in a $56 \%$ reduction in primary tumor growth rate compared to controls receiving scrambled protein. Moreover, this coincided with a $42 \%$ reduction in vascular endothelial growth factor (VEGF) protein expression and $30 \%$ reduction in $\mathrm{p}-\mathrm{AKT} /$ AKT expression [32]. Furthermore, in various cancer models metastasis of cancer cells was revealed to be mediated by CXCR4 activation and directed migration towards CXCL12 expressing organs [33-37]. Experimental metastatic mouse models have provided evidence that targeting CXCR4 impairs cancer cell metastasis [29, 32, 37-42]. The CXCR4 inhibitor AMD3100 is FDA approved for use in patients with non-Hodgkin's lymphoma and multiple myeloma. It is registered to be used as stem cell mobilizer [43] and is tested as investigational agent as anticancer drug for other cancers [44].

For VHL-related hemangioblastoma, targeted therapy against CXCR4 and VEGFA could potentially be combined with conventional therapy as VHL-related disease is multiple and lesions often reoccur after surgery [45-47]. Besides, as VHL disease is an autosomal dominant multisystem neoplastic syndrome [48, 49] targeted therapy would be a good option to treat VHL disease at other sites, for example (metastasizing) renal cell carcinoma. We also found VEGFA overexpressed in stromal hemangioblastoma cells as compared to normal surrounding brain tissue. Bevacizumab, an anti-VEGFA monoclonal antibody, has been extensively investigated in several settings, ranging from single agent treatment to combined modality approaches in both recurrent and newly diagnosed malignancies [50]. Preclinical experiments show that the combination of AMD3100 and bevacizumab may help prevent the growth of certain tumors like gliomas [51, 52]. In the presence of HIF $1 \alpha$ bone marrow-derived CD45 + myeloid cells containing Tie2+, VEGFR1+, CD11b+, and F4/80+ subpopulations, as well as endothelial and pericyte progenitor cells promote neovascularization, party trough increase in CXCL12, the ligand of CXCR4. MMP-9 activity of bone marrow-derived CD45+ cells is essential to initiate angiogenesis by increasing VEGF bioavailability [51]. Impaired pVHL fails to degrade HIF $1 \alpha$ resulting in increased VEGFA levels and therefore combined CXCR4 and VEGFA inhibition could be of potential benefit for VHL patients. A phase I study of the CXCR4 inhibitor plerixafor and bevacizumab is ongoing for patients with recurrent high-grade gliomas (NCT01339039). This combination could be potentially of high interest for both VHL related and sporadic patients with hemangioblastoma.

\section{Conclusions}

CXCR4, CXCL12, and VEGFA were all overexpressed in hemangioblastomas as compared to normal surrounding tissue. Sporadic hemangioblastomas express more CXCR4 as compared to VHL-related hemangioblastoma. The difference in CXCR4 expression was not explained by size, or VHL mutation and/or hypermethylation. CXCR4 expression in hemangioblastoma tissue potentially creates treatment opportunities with drugs specifically targeting CXCR4 expressing cells.

Acknowledgments This work was supported by the Jan Kornelis de Cock Stichting and an UEF-JSM Talent grant by the Van de MeerBoerema foundation. We want to thank R. van Leeuwen and B. Wisman for their help with the MSP analysis, L. Huijgen for support with the immunohistochemistry and collection of tissue samples and Nathalie Kliphuis for scoring the immunohistochemistry stainings.

\section{Compliance with ethical standards}

Conflict of interest The authors report no conflicts of interest that could be perceived as prejudicing the impartiality of the research reported.

Open Access This article is distributed under the terms of the Creative Commons Attribution 4.0 International License (http://crea tivecommons.org/licenses/by/4.0/), which permits unrestricted use, distribution, and reproduction in any medium, provided you give appropriate credit to the original author(s) and the source, provide a link to the Creative Commons license, and indicate if changes were made.

\section{References}

1. Maher ER, Neumann HP, Richard S (2011) von Hippel-Lindau disease: a clinical and scientific review. Eur J Hum Genet 19(6):617-623

2. Maxwell PH, Wiesener MS, Chang GW et al (1999) The tumour suppressor protein VHL targets hypoxia-inducible factors for oxygen-dependent proteolysis. Nature 399(6733):271-275

3. Semenza GL (2003) Targeting HIF-1 for cancer therapy. Nat Rev Cancer 3(10):721-732

4. Staller P, Sulitkova J, Lisztwan J, Moch H, Oakeley EJ, Krek W (2003) Chemokine receptor CXCR4 downregulated by von Hippel-Lindau tumour suppressor pVHL. Nature 425(6955):307-311

5. Bergers G, Hanahan D (2008) Modes of resistance to anti-angiogenic therapy. Nat Rev Cancer 8(8):592-603

6. Burger JA, Peled A (2009) CXCR4 antagonists: targeting the microenvironment in leukemia and other cancers. Leukemia 23(1):43-52

7. Orimo A, Gupta PB, Sgroi DC et al (2005) Stromal fibroblasts present in invasive human breast carcinomas promote tumor growth and angiogenesis through elevated SDF-1/CXCL12 secretion. Cell 121(3):335-348

8. Zagzag D, Krishnamachary B, Yee H et al (2005) Stromal cellderived factor-1alpha and CXCR4 expression in hemangioblastoma and clear cell-renal cell carcinoma: von Hippel-Lindau loss-of-function induces expression of a ligand and its receptor. Cancer Res 65(14):6178-6188 
9. Zeng Z, Shi YX, Samudio IJ et al (2009) Targeting the leukemia microenvironment by CXCR4 inhibition overcomes resistance to kinase inhibitors and chemotherapy in AML. Blood 113(24): 6215-6224

10. Poulsen ML, Budtz-Jorgensen E, Bisgaard ML (2010) Surveillance in von Hippel-Lindau disease (vHL). Clin Genet 77(1):4959

11. Lammens CR, Aaronson NK, Hes FJ et al (2011) Compliance with periodic surveillance for von-Hippel-Lindau disease. Genet Med 13(6):519-527

12. Hes FJ, van der Luijt RB (2000) von Hippel-Lindau disease: protocols for diagnosis and periodical clinical monitoring. National von Hippel-Lindau disease working group. Ned Tijdschr Geneeskd 144(11):505-509

13. VHL Family Alliance (2012) The VHL handbook, what you need to know about VHL. 4th edn. CreateSpace Independent Publishing Platform, pp 46-51

14. van Dongen JJ, Langerak AW, Bruggemann M et al (2003) Design and standardization of PCR primers and protocols for detection of clonal immunoglobulin and T-cell receptor gene recombinations in suspect lymphoproliferations: report of the BIOMED-2 concerted action BMH4-CT98-3936. Leukemia 17(12):2257-2317

15. Pan J, Mestas J, Burdick MD et al (2006) Stromal derived factor1 (SDF-1/CXCL12) and CXCR4 in renal cell carcinoma metastasis. Mol Cancer 5:56

16. Liang X, Shen D, Huang Y et al (2007) Molecular pathology and CXCR4 expression in surgically excised retinal hemangioblastomas associated with von Hippel-Lindau disease. Ophthalmology 114(1):147-156

17. Chan CC, Collins AB, Chew EY (2007) Molecular pathology of eyes with von Hippel-Lindau (VHL) disease: a review. Retina 27(1):1-7

18. Song Y, Constantinescu A, Mason RP (2002) Dynamic breast tumor oximetry: the development of prognostic radiology. Technol Cancer Res Treat 1(6):471-478

19. Zhao D, Constantinescu A, Hahn EW, Mason RP (2002) Differential oxygen dynamics in two diverse dunning prostate R3327 rat tumor sublines (MAT-Lu and HI) with respect to growth and respiratory challenge. Int J Radiat Oncol Biol Phys 53(3):744756

20. Glasker S, Bender BU, Apel TW et al (2001) Reconsideration of biallelic inactivation of the VHL tumour suppressor gene in hemangioblastomas of the central nervous system. J Neurol Neurosurg Psychiatry 70(5):644-648

21. Moore LE, Nickerson ML, Brennan P et al (2011) von HippelLindau (VHL) inactivation in sporadic clear cell renal cancer: associations with germline VHL polymorphisms and etiologic risk factors. PLoS Genet 7(10):e1002312

22. Gijtenbeek JM, Jacobs B, Sprenger SH et al (2002) Analysis of von Hippel-Lindau mutations with comparative genomic hybridization in sporadic and hereditary hemangioblastomas: possible genetic heterogeneity. J Neurosurg 97(4):977-982

23. Kanno H, Kondo K, Ito S et al (1994) Somatic mutations of the von Hippel-Lindau tumor suppressor gene in sporadic central nervous system hemangioblastomas. Cancer Res 54(18):48454847

24. Lee JY, Dong SM, Park WS et al (1998) Loss of heterozygosity and somatic mutations of the VHL tumor suppressor gene in sporadic cerebellar hemangioblastomas. Cancer Res 58(3):504-508

25. Lemeta S, Pylkkanen L, Sainio M et al (2004) Loss of heterozygosity at $6 q$ is frequent and concurrent with $3 p$ loss in sporadic and familial capillary hemangioblastomas. J Neuropathol Exp Neurol 63(10):1072-1079

26. Oberstrass J, Reifenberger G, Reifenberger J, Wechsler W, Collins VP (1996) Mutation of the von Hippel-Lindau tumour suppressor gene in capillary haemangioblastomas of the central nervous system. J Pathol 179(2):151-156

27. Tse JY, Wong JH, Lo KW, Poon WS, Huang DP, Ng HK (1997) Molecular genetic analysis of the von Hippel-Lindau disease tumor suppressor gene in familial and sporadic cerebellar hemangioblastomas. Am J Clin Pathol 107(4):459-466

28. Sehgal A, Keener C, Boynton AL, Warrick J, Murphy GP (1998) CXCR-4, a chemokine receptor, is overexpressed in and required for proliferation of glioblastoma tumor cells. J Surg Oncol 69(2):99-104

29. Muller A, Homey B, Soto H et al (2001) Involvement of chemokine receptors in breast cancer metastasis. Nature 410(6824):50-56

30. Rempel SA, Dudas S, Ge S, Gutierrez JA (2000) Identification and localization of the cytokine SDF1 and its receptor, CXC chemokine receptor 4, to regions of necrosis and angiogenesis in human glioblastoma. Clin Cancer Res 6(1):102-111

31. Kioi M, Vogel H, Schultz G, Hoffman RM, Harsh GR, Brown JM (2010) Inhibition of vasculogenesis, but not angiogenesis, prevents the recurrence of glioblastoma after irradiation in mice. J Clin Invest 120(3):694-705

32. Hassan S, Buchanan M, Jahan K et al (2011) CXCR4 peptide antagonist inhibits primary breast tumor growth, metastasis and enhances the efficacy of anti-VEGF treatment or docetaxel in a transgenic mouse model. Int J Cancer 129(1):225-232

33. Taichman RS, Cooper C, Keller ET, Pienta KJ, Taichman NS, McCauley LK (2002) Use of the stromal cell-derived factor-1/ CXCR4 pathway in prostate cancer metastasis to bone. Cancer Res 62(6): 1832-1837

34. De Falco V, Guarino V, Avilla E et al (2007) Biological role and potential therapeutic targeting of the chemokine receptor CXCR4 in undifferentiated thyroid cancer. Cancer Res 67(24):11821-11829

35. Wang Z, Ma Q, Liu Q et al (2008) Blockade of SDF-1/CXCR4 signalling inhibits pancreatic cancer progression in vitro via inactivation of canonical wnt pathway. Br J Cancer 99(10): 1695-1703

36. Bartolome RA, Ferreiro S, Miquilena-Colina ME et al (2009) The chemokine receptor CXCR4 and the metalloproteinase MT1MMP are mutually required during melanoma metastasis to lungs. Am J Pathol 174(2):602-612

37. Zeelenberg IS, Ruuls-Van Stalle L, Roos E (2003) The chemokine receptor CXCR4 is required for outgrowth of colon carcinoma micrometastases. Cancer Res 63(13):3833-3839

38. Kim SY, Lee CH, Midura BV et al (2008) Inhibition of the CXCR4/CXCL12 chemokine pathway reduces the development of murine pulmonary metastases. Clin Exp Metastasis 25(3): 201-211

39. Smith MC, Luker KE, Garbow JR et al (2004) CXCR4 regulates growth of both primary and metastatic breast cancer. Cancer Res 64(23):8604-8612

40. Huang EH, Singh B, Cristofanilli M et al (2009) A CXCR4 antagonist CTCE-9908 inhibits primary tumor growth and metastasis of breast cancer. J Surg Res 155(2):231-236

41. Porvasnik S, Sakamoto N, Kusmartsev S et al (2009) Effects of CXCR4 antagonist CTCE-9908 on prostate tumor growth. Prostate 69(13):1460-1469

42. Schimanski CC, Bahre R, Gockel I et al (2006) Dissemination of hepatocellular carcinoma is mediated via chemokine receptor CXCR4. Br J Cancer 95(2):210-217

43. DiPersio JF, Uy GL, Yasothan U, Kirkpatrick P (2009) Plerixafor. Nat Rev Drug Discov 8(2):105-106

44. Domanska UM, Kruizinga RC, Nagengast WB et al (2013) A review on CXCR4/CXCL12 axis in oncology: no place to hide. Eur J Cancer 49(1):219-230

45. Maher ER, Webster AR, Moore AT (1995) Clinical features and molecular genetics of von Hippel-Lindau disease. Ophthalmic Genet 16(3):79-84 
46. Richard S, Campello C, Taillandier L, Parker F, Resche F (1998) Haemangioblastoma of the central nervous system in von HippelLindau disease. French VHL study group. J Intern Med 243(6):547-553

47. Slater A, Moore NR, Huson SM (2003) The natural history of cerebellar hemangioblastomas in von Hippel-Lindau disease. AJNR Am J Neuroradiol 24(8):1570-1574

48. Linehan WM, Lerman MI, Zbar B (1995) Identification of the von Hippel-Lindau (VHL) gene: its role in renal cancer. JAMA 273(7):564-570

49. Lonser RR, Glenn GM, Walther M et al (2003) von HippelLindau disease. Lancet 361(9374):2059-2067

50. Amit L, Ben-Aharon I, Vidal L, Leibovici L, Stemmer S (2013) The impact of bevacizumab (avastin) on survival in metastatic solid tumors - a meta-analysis and systematic review. PLoS ONE 8(1):e51780

51. Du R, Lu KV, Petritsch $\mathrm{C}$ et al (2008) HIF1alpha induces the recruitment of bone marrow-derived vascular modulatory cells to regulate tumor angiogenesis and invasion. Cancer Cell 13(3):206220

52. Ping YF, Yao XH, Jiang JY et al (2011) The chemokine CXCL12 and its receptor CXCR4 promote glioma stem cell-mediated VEGF production and tumour angiogenesis via PI3K/AKT signalling. J Pathol 224(3):344-354 